Media Industries 6.2 (2019)

\title{
Informality in the Time of Platformization
}

\author{
Akshaya Kumar \\ INDIAN INSTITUTE OF TECHNOLOGY INDORE ${ }^{1}$ \\ akshaya.kumar [AT] iiti.ac.in
}

\begin{abstract}
In this article, I argue that formalization, not as a simple economic fact ascertained by licensed product sale but as a force determining the performative temperament, stands at odds with the "vernacular" media in general, and Bhojpuri media in particular. That is why, even as online views multiply and offline data kiosks continue to thrive, the performative informality of the live concert continues to mobilize millions across remote villages, small towns, and big cities. What can be rendered in terms of new technologies and platforms enabling specific sort of publics must not overwrite another adjacent trajectory-that of informality, as a performative excess, as a cultural cache of communitarian solidarity particularly built around language affinities, as a visceral aspect of music economy, seeking its life outside the formal straitjacket. The live concerts then stand not in opposition to, but adjacent to the platformization and formalization of the media economy.
\end{abstract}

Keywords: Informal Media, Indian Media, YouTube, Online Video

In the 1980s, the emergence of the audiocassettes led to an explosion of recorded music throughout north India. Although north India is generally seen as the Hindi-speaking preponderance of India's linguistic geography, it is profoundly marked by many "dialects" of this composite language, most of which are older than modern standard Hindi and remain closely linked to specific regions and population segments. In these so-called dialects, "vernacular" musical traditions blending "folk" and "modern" motifs were greatly enhanced and expanded by the advent of portable media devices from the 1980s onward. Vernacular singer-performers began to record albums in makeshift studios in Garhwali, Haryanvi, Bhojpuri, and other subregional languages on a large scale. ${ }^{2}$ The volume of production has kept expanding even as the recording and playback technologies have shifted from audiocassettes, to music videos (on video compact disks [VCDs] first and DVDs later), to digital downloads for mobile phones. ${ }^{3}$ 
In recent years, mobile phone has become the primary portable device on which subregional music videos thrive, whether the content is transferred offline or streamed online. ${ }^{4}$ The larger part of this ecology of audiocassettes, disks, microSD cards, and "Chinese" mobile phones operates outside the formal economy. They constitute the thriving "do-it-yourself" segment of media bazaars, where repairing, refurbishing, and reusing are the hallmarks of electronic merchandise retail. In this informal economy, the hardware is often "dodgy" and the "software" of recorded music-shot in studios or at the live concerts-is typically transacted without any concern for copyright whatsoever.

The eruption of vernacular media economy has fundamentally altered the media production, distribution, and consumption landscape across north India. Bhojpuri media in particular has spread across the length and breadth of the country on account of labor migration. In the festival season, one may witness numerous concert performances in the suburbs of Delhi and Mumbai, but also around other large cities of peninsular India. This complicates the "regionality" of vernacular media, since it is shaped as much by the linguistic and cultural wealth of its "native" region-western Bihar and eastern Uttar Pradesh-as by the traffic of personnel, imaginaries, and devices. ${ }^{5}$ Vernacular media production has traditionally been based out of Delhi studios, but in the last decade, recording studios, mixing labs, and various ad hoc production facilities have mushroomed all across the Bhojpuri-speaking region. The relentlessly playful reconfiguration of regionality-with respect to the audience demography-lends Bhojpuri media a curious slippery character that negotiates the national and the regional in site-specific ways. For example, in the suburbs of Mumbai, the artists may not deter from singing a lavani (an erotic performance constitutive of the Marathi Tamasha) or addressing the audience as uttar bhartiya (north Indians), instead of Bhojpuri bhaiyon (brothers).

Informality has been the lifeblood of vernacular media economies, where freely sharing devices and copying media are routine practice. ${ }^{6}$ In fact, much of the media content thriving in these economies only finds distribution through informal networks that operate on the margins of formal retail distribution. For a hawker on a pavement in Patna, it means not having to contact a corresponding wholesaler, who would call the Delhi-based production office to eventually receive more copies of a disk witnessing a surge in demand. They can simply respond to the immediate demand by making more copies, without taking the undue risk of keeping extra inventory. Informality in the distribution chain invariably reflects the informal working conditions of marginal sellers as well as the purchasing power and technological access of the buyers. Informal distribution chains allow vernacular media markets to operate on the margins of larger formal markets without having to endure the same risks of capital flow and investment, given that the financial securities required to hedge those risks tend to be unavailable to them.

In a sense, the juxtaposition of formal and informal media markets could be thought of as product-driven versus services-driven supply. Formal product markets are guided by production infrastructures, whereas informal markets are driven by the service demand from customers. In a formal product-driven market, the products are designed as per the existing knowledge of consumer demand and then supported through the retail chain with adequate advertising push to ensure sales revenue. The informal markets pushing a services-driven commodity, untethered as they are to the big capital backing its retail distribution and 
advertising, tend to unhinge themselves from the production-end calculations of consumer demand. As a real-time service to the retail market, products are "copied into" service provision on the pavements. Thus, it is important to understand that a key characteristic of informal media markets is that they are much less sensitive to the advertising-driven product differentiations which operate at the heart of capital-commodity dynamic of market economies. Partly, this has to do with the broken links between production and distribution ends, which render informal markets their speculative character, outside of the sophisticated consumer analytics formal markets are increasingly saturated with.

This ethos of informal economy both predates and informs the shopfront logics of the digital platforms that have emerged in India over the past decade. Even though discourses of platform economy have become oriented to digital ecosystems, there is no reason why we cannot develop a broader account of platform economy. Accordingly, this article investigates the interactions between the distribution arsenal of platform economies and the informal media markets that had emerged previously as "local" pockets of growth outside the centrally controlled distribution of mainstream media. A narrative of disruption prompts us to ask, How does the rise of platform economy disrupt or reorganize these informal markets? A more evolutionary perspective prompts us to ask, How do consumer formations in these informal markets inform the trajectory of platformization in India? This article, therefore, gives some critical consideration as to whether we are witnessing the beginning of the end of informal media markets or their profusion via digital domains as web connectivity penetrates deeper.

As I will establish, the live concerts where thousands gather to witness the artists perform through the night are a key site that escapes the grip of platformization. Not only are such concerts the kernel of activity within vernacular media economy, they are also a thriving site of informal exchanges that slip outside the archival aggregation, either in an ad hoc manner at the arbitrage platforms or via algorithmic accumulation at YouTube. Delineating three somewhat distinct tendencies of archive, I discuss how the live concerts work against the distributive control of platform economies by privileging the informal performative presence over the relay of staged, orchestrated, and edited media commodities. The article, therefore, highlights one of the central features of vernacular media that sits in a fundamental conflict with platform economies in media industries.

\section{Arbitrage Platforms: From Audio Cassettes to Download Kiosks}

Before the advent of audio cassettes, the centerpiece of media ecology in rural and semiurban north India was the radio or, its younger cousin, the transistor. Men and women would congregate around the radio and perform domestic chores while listening to songs, news, or special programs to address agrarian matters or host a celebrity. All India Radio curated programs featuring film songs as the key entertainment packages on the device. They would be old and new Hindi film songs produced in Mumbai. With the entry of audio cassettes, "twoin-ones" offering both radio and cassette functions replaced the radio as the most desirable domestic media device. Importantly, song lists could now be curated by the owner of the cassette device, and recordable cassettes with song collections of personal favorites came 
into vogue. Even more importantly, cassettes allowed numerous singers to record themselves through production studios and access diffuse media markets neglected by the major companies. This small revolution invigorated the music industry in north India, a tale well recounted in Peter Manuel's Cassette Culture. ${ }^{7}$ As a modality of both production and distribution, analogue tape and audio cassettes were revolutionary. As opposed to the handful of music companies that had previously aligned their music catalogs to a mass market, an explosion of vernacular music industries in subregional "dialects" ushered in a host of genres, studios, artists, and audiences.

This expansion was, in many ways, akin to what is now labeled as platform capitalism. For the vernacular media, a new interlocking ecology was instantiated in which participants were drawn in and aggregated via new shopfronts (studios, retail stores, performance stages). As Manuel has narrated, political and religious campaigns would try to capture the public formed at the sites of musical performance. The chart-topping songs produced for a political or religious campaign reflected the repurposing potential of the vernacular media commodity via public spectacles of popular support. Thus, the celebrity performer became the most vital mediator across platforms and ideological grooming in a series of informal domains. As in platform business models, these "festive" transactions became subject to the emergence of arbitrage platforms toward monetizing the congregations of live audiences. ${ }^{8}$ The audio cassette constituted a platform that could replicate and repurpose the site of live performances, thereby instantiating strategic arbitrage platforms such as a neighborhood Ramayan Path, akhand jagran, or a political rally. Unlike digital platforms of the present, there was no algorithmic aggregation at the monetization end. Arbitrage platforms without algorithms were the hotbed of sharing, the basis of communal relations, and the lifeblood of informal economy. Thus, the calculation and billing of arbitrage, in a manner of speaking, was crude, manual, and speculative. These platforms were, nonetheless, geared toward increasing diversity and the multidirectional growth of consumption sites, devices, and retail.

The next major iteration in this trajectory of platformization, the VCD, appended the music video to the sonic data previously circulated on cassettes. The cassettes did not die out for a long while, however, and a majority of VCDs were simply direct recordings of live performances. In this ecosystem, Bhojpuri music interlocked with Garhwali, Himachali, Maithili, and Haryanvi music, primarily in the Delhi studios, while the audiovisual effects overlapped with various other video-making practices, as in wedding and birthday videos, or religious and political campaigns. Yet, as another arbitrage platform, VCD and later DVD were further constituents of an arbitrage media economy that was not consolidated at the capital ownership end. Cassettes, VCDs, and DVDs nonetheless enabled enormous growth in artists, songs, and performances through an economy that was interlocking in terms of flow of personnel and tendencies, but fragmented in terms of capital and control. ${ }^{9}$ India's "festival season," from Chhath all the way to Holi, would witness an annual deluge of songs and music videos flooding the market, from which a more limited stock of tunes, melodies, and orchestration schemes would be repurposed from the concert stage to film songs. The volume of content could therefore be misleading, since it only signified the flow across the interlocking arbitrage economy, in which platforms suspended in a shifting media ecosystem variously attended to the expanding consumer base of vernacular music. 
While the VCDs/DVDs or cassettes required players that were often owned by a group, cheap mobile phones gradually replaced them as a more individually oriented interface for storage, recording, and playing media files. Given the weakness or unavailability of network connectivity, the success of the "smart" mobile phone among the working classes was primarily on account of its usage as a powerful media platform. The key site for feeding these mobile phones was the download kiosk at a mobile recharge shop. ${ }^{10}$ A vendor would typically need only "a laptop full of songs and videos, a dongle to connect a memory card through a USB port, and some format conversion software."11 Mukherjee and Singh wrestle with this question with respect to the microSD cards that are central to the informal economy of download kiosks:

At one level, memory cards are platforms that consist of hardware and software components that permit music to be recorded, stored, and played. At another level, memory cards span different emerging platform systems of audio/DVD players, mobile phones, and TV sets and become part of these various sensory infrastructures. Memory cards reconfigure various mobile media assemblages and create an ecosystem of platforms around them ... Indeed, the platform ecosystem consisting of Chinese DVD players, audio players with Pepsi or Axe cases, and iPod knock-offs that memory cards inhabit are accompanied by untaxed services, counterfeit goods, fake accessories, and unlicensed goods. Nonetheless, these informal platform ecosystems also grow and innovate just like industry platforms, albeit in different ways and through different channels. And just like digital algorithm-and-interface-based online platforms, the not-always-online or rather offline digital platforms ... operate according to (informal) economic/business models, are characterized by an ecosystem/network logic, and provide spaces for users to participate and interact. ${ }^{12}$

Rather than determining whether the mobile phone or the microSD cards should be identified as platforms, Mukherjee and Singh argue for a platform ecosystem which may not be entirely web-based. Taking their fundamental premise, that platform functions need to be understood independently of their code-centric data structure, I argue that we must also distinguish between platforms and platform economies. Thus, while I conceptualize audio cassettes, VCDs, digital versatile disks, mobile phones, and microSD cards as arbitrage platforms-parts of an elaborate interlocking network in which small differentials are monetized-I also argue that they are not yet integrated into a platform economy. The latter outcome hinges upon algorithms of aggregation and value creation via which modalities of ordinary sharing are dis-embedded from existing social economies and re-embedded in new transactional forms built for digital systems, which render them legible as transactions with a definite footprint. ${ }^{13}$ As long as arbitrage platforms remain outside algorithmic governance, they constitute platforms that are relatively independent of a platform economy.

As such, the aim of the latter is to recruit the former into algorithmic governance, or what Beller calls computational capital. ${ }^{14}$ As we go along, therefore, it is important to remember that even though the platform economy produces and sets into motion surplus time, attention, labor, and property, platforms are prerequisites for, rather than derivative of, the digital drive for data accumulation. Couldry and Mejias have also argued that the platform "produces the social for capital, that is, a form of 'social' that is ready for appropriation and exploitation for value as data, when combined with other data similarly appropriated."15 


\section{Subscription versus Advertising}

Platform economy is driven by the desire to occupy, aggregate, and control informality and its communal life, by breaking it down to individuals that can be plotted within the formal domain of computational capital. The two clinching revenue models of the platform economy in the media industry are subscription- or advertising-based. In the case of the former, captive paying customers are allowed access to content exclusive to the platform. In the latter case, the content is made accessible for free, at the cost of occupying consumers' attention for advertising merchandise. While the former is a relatively straightforward service to paying customers, the latter is a monopoly model where the user analytics becomes the product, which is accumulated and sold to the advertisers, who then indulge in targeted advertising. ${ }^{16}$ Targeted advertising is derived from psychographic and demographic profiles append to the platform's "knowledge." In India, YouTube has become the preeminent advertising-based platform for vernacular media consumption within the online sphere. As a content platform, the repository offered by YouTube is unmatched. It is the preeminent platform to access all vernacular media content in Bhojpuri, Haryanvi, Santhali, Uttarakhandi, Himachali, and other "dialects" of Hindi while also carrying most of the official television channels and copyrighted content. It also conveys the equivalent content in the non-Hindispeaking regions of India, as Srinivas notes in the context of Telugu language content from south India:

YouTube's status as the official repository of the local media industry has come into sharp focus. Today, major Telugu language television news channels including TV9, TV5 and ABN Andhra Jyothi, beam live on YouTube. All major Telugu television channels upload content on their official YouTube channels. For their part, film production and packaged media (VCD/DVD/Blu-ray) distribution companies have put out hundreds of film titles on their YouTube channels. More recent titles are available in the HD versions with English subtitles. Almost all Telugu YouTube content is freely accessible from Indian IP addresses. ${ }^{17}$

The multichannel network (MCN) architecture of YouTube has been crucial to this spongelike absorption of entire media spectrums across the globe. Lobato explains the shift from singular videos to MCNs in YouTube's cultural-economic logic after the takeover by Google in 2006:

The early YouTube was characterized by the promise of direct, DIY communication with a global audience, and its corporate image was that of the upstart outsider. Today, YouTube is thoroughly mainstream. Its signature innovations-revenue sharing of video advertising, automated content ID and open viewer metrics - have become the basis for a massive commercial ecosystem ... Every surface of YouTube-display ads, overlays, comments, pop-ups and not least the mise-en-scene of the videos-has been opened for business in one way or another. This process has involved not only Google but a wide range of other actors, including advertising agencies, data analytics firms, digital marketing companies and spambots, as well as hundreds of thousands of non-professional producers... MCNs are intermediary firms that operate in and around YouTube's advertising infrastructure. A common business model is for MCNs to sign up a large number of popular channels to their network, then, using YouTube's content management system, to sell advertising and crosspromote their affiliated channels across this network, while also working with popular YouTube celebrities to develop them into fully fledged video brands... As well as having a commercial 
relationship with YouTube, which works direct with popular creators via the Partner programme, many YouTubers now sign contracts with MCNs to increase their audience and advertising income and agree to split their ad revenue with the MCN accordingly. ${ }^{18}$

While it may seem to be unchanged as a platform in terms of the screen interface, the architectural and algorithmic shift in YouTube has made fundamental changes on at least two accounts: (1) targeted advertising for the absorption of ad revenue, and (2) privileging copyrighted content for monetization. Lobato observes that the MCNs "aggregate ad sales across the platform, increase the quality of uploaded videos, reduce intellectual property infringements and generally make it a more appealing space for advertisers." ${ }^{\text {.19 }}$ The MCNs, therefore, provide "non-professional creators with technical, promotional and advertising services in exchange for a commission (20-50\% of net advertising revenues)-a classic intermediary function." ${ }^{20}$ The algorithmic scalability and ad placement offer a well-rounded platform ecosystem that helps content creators garner attention in the YouTube ocean. MCNs, as a search-optimization service tailored for YouTube, provide "advice on titles, keywords and metadata and to associate content with topical and frequently searched-for terms." 21 However, they privilege specific consumer "verticals" such as fashion, cooking, and tech review channels for their cross-promotional potential and "their clear link to specific advertising markets and demographics." 22 In an advertising-based interlocking ecosystem, information markets, regulatory structures, and cultural dynamics appear to interpenetrate across digital media (mobile and web-based applications) in a platform economy. One of the key ideas here is to enable, shape, and commodify new forms of sociability. ${ }^{23}$

Despite the apparent promise of industry consolidation, content aggregation, and distribution of ad revenues, the absence of such consumer verticals for vernacular media content, which is mainly addressed to working-class migrants, complicates the picture significantly. The consumer analytics on vernacular media content does not greatly encourage the crosspromotional design of vertical integration and cross-promotion. The intermediary function to aggregate the informal economy and include it within the formal fold thus comes up against the limitations of advertising-driven media industries. One of the key roles of platformization, after all, is aggregating people as analytics to be sold to advertisers. Yet, the drive to vertically integrate, standardize, and control the informal economy also empowers those holding franchise relationships, even if the dynamic is heavily weighted in favor of the franchisor. ${ }^{24}$ India's informal video production, which earlier revolved around audio cassettes or VCDs/DVDs, now primarily focuses on YouTube channels (Wave Music, Angle Music, and Ganga Cassettes being the prime aggregators) and the offline video sharing economy. Of course, the smaller MCNs are rarely interested in setting up their own player platform, since it is expensive to build and is entirely taken care of by YouTube. Questions of exploitation and regulation are thus at the heart of the post-MCN YouTube architecture.

It is important, however, to highlight key shifts that platformization via YouTube has introduced within India's vernacular media industries. First, the MCNs work as portfolio economies, in which generic diversity of content becomes crucial as a risk mitigation tactic, even though the biggest beneficiaries of aggregation remain the major film stars. ${ }^{25}$ Cross- $^{-}$ promotional interests and algorithmic recommendations ensure that users navigate the channel portfolios in trajectories that best serve the interests of YouTube. Second, MCN-led architecture does not only serve its own enclosed interests, since it strategically 
outmaneuvers the erstwhile singular video design. Instead of risking one's creative work and livelihood by dumping it in the YouTube ocean as a singular entity, artists are compelled to enter a contractual arrangement with the aggregators, while consumers are compelled to follow a new mode of guided consumption. Without the navigation function of the channels, no video can thrive in the ostensibly "free" world of YouTube. Third, YouTube is at the heart of the platformization of vernacular music economy in terms of distribution, and it unflinchingly privileges the formalization of the informal economy. Fourth, in terms of arbitrage, YouTube only sits beside the thriving informal economy operating as a mode of public spectacle. Thus, while it is undeniable that successive media technologies have aided the exponential rise of vernacular music, the centrality of live concerts has never conceded preeminence to platformization. We must, therefore, keep the live concerts in focus to understand the broader life of informality in the time of platformization.

\section{The Live Concerts}

Informality is not a mere object of scholarly fetish in this discussion, but a step outside the control exercised by the production/distribution structure. As most media production tends to be capital-intensive, its production costs and distribution infrastructure remain in the hands of small cartels. The life of subregional media began as an initiative outside this control of capital and distribution, when the cassettes and innumerable live concerts of Manoj Tiwari inaugurated the Bhojpuri mass audience. Shall we simply concede that these spaces outside the formal sector have come full circle to be consumed by the formalization of webbased platforms? Not quite, because informality as a performative temperament continues to define vernacular media in general, and Bhojpuri media in particular. The live concerts, despite the newfound glitz and mounting political and religious patronage, recall and restore direct communication between artists and their audience. It is this essential performative substance that portable media devices promise to capture as arbitrage platforms. That is why, even as online views multiply relentlessly and offline data kiosks ensure the last mile "connectivity," the performative informality of the live concert continues to mobilize millions across remote villages, small towns, and big cities. The performative excess triggers communitarian solidarities built around language affinities. The visceral nature of live concerts that witness thousands congregate for a nightlong feast of performative surplus are regularized encounters operating outside the formal straitjackets.

Most of these live concerts are advertised on account of a relatively well-known singerperformer, but a whole bunch of younger singers, dancers, and anchors hold the crowd's attention for the bulk of the event. Patriotic, devotional, and sleazy genres are blended together with a lot of direct conversation between the anchors or singers on stage and the crowds. Unlike Bollywood extravaganzas on "world tours" where the stage remediates the screen, the Bhojpuri live concerts are far more intimate and receptive to the crowd. The life of informality in live concerts, therefore, revolves around the fact that performers submit to the unpredictability of popular vote. Instead of serving them a film or album product, they orient themselves toward the service of popular demand. The live concerts, therefore, invert the formal grid in which popular culture operates as an industrial formation and repeatedly underline the fundamental alterity of vernacular mediation. The concert is also the kernel of 
communal solidarity as the basis of vernacular media's success. It is the preeminent site where a plea is submitted by an artist to the people and his candidature ratified for further outgrowth.

A whole range of hereditary genres and artists (such as Dhobi Geet and Ahirauwa Nach), however, only perform in the neighboring towns and villages. Increasingly, though, the younger generation of performers do not wish to confine themselves to hereditary genres. Unlike a few decades ago, when expertise within a genre was the most desirable attribute, the performative virtuosity to switch across genres and styles is increasingly the most desirable component of informality that thrives in concert performances. One of the key battlegrounds of such virtuosity is the duel, where performers or their teams engage in a lively contest. Prakash writes about the genre:

Dūgolā, also known as laykārì muqābalā (lyrical rivalry) or lokgīt muqābalā ("folk" song competition), is a popular performance of the Magahi and Bhojpuri regions of Bihar and Uttar Pradesh, in which two or more singers-performers rival each other. Like a stand-up comedian, the dügolā performer sings, dances, cracks jokes, tells stories and often composes new song and stories impromptu during a performance. There are similar structures of performance across India with different names, such as kobigān in Bengal, and ladāi, muqāblā, and akhārā in Uttar Pradesh and Madhya Pradesh... Because of its competitive nature, dügolā inherits strong elements of sports and play.... The performance gives space to new singer-performers to emerge, as well as for older performers to return and share years of acquired experience with the audience... Dügolā performers sing, dance, and freely draw from all possible sources. They often alter existing musical compositions and compose spontaneously to score points against the rival group. Performersingers often break into a quarrel, sing insults, and demonstrate power and valour through masculine gestures. ${ }^{26}$

Even though many of these dugola recordings are available on YouTube and on DVDs with various vendors, the substance of performative virtuosity in direct conversation with crowd is lost in those arbitrage platforms. Yet, toward the end of the YouTube videos of these events, the flicker at the bottom displays phone numbers to contact the production company and artists for organizing live concerts. The patronage for such shows could vary from private patrons at a village or town gathering to a more political or religious patronage with multiple stakeholders. In that respect, the live concerts stand not in opposition but adjacent to the affordances of platformization and its attendant formalization of the media economy. They recruit platforms as advertising agents while continuing to sit beside, fiddling with the unpredictable, ephemeral, ribaldrous, and sovereign declarations of popular will. Therefore, the informality and unpredictability of the live concerts challenge the structure of archival tendencies of vernacular media. The archive, after all, determines the nature of community formation and politics of accessing the shared-or communal, in a political sense-wealth. ${ }^{27}$

\section{Three Ideas of the Archive}

As discussed above, the shift from audio cassettes and VCDs/DVDs toward mobile phones and microSD cards marked a shift from communal viewing toward more individual 
consumption. Even if cassettes and disks were individually owned, the devices on which they were played were often collectively owned by the migrant workers in a shared accommodation. Mobile phones, however, are largely personal devices. Even when women or teenage boys borrow the phones shared among family members, or from their elder brothers, they very often use their own microSD cards to personalize the device. Mukherjee and Singh offer some insights:

Despite the ease and seamlessness in streaming music, the content remains with the content providers, which is not the case with memory cards. People have a personal attachment to their microSD cards; they keep them safe from scratches, they love to talk about their content (unless some of it is censored/pornographic), and, as such, it perpetuates a personal archiving practice. These personal archiving practices are marked by variation in the frequency of visits to the download vendor and a preference regarding the type of uploading. ${ }^{28}$ (Emphasis added)

However, more interesting hybrids such as Chinese-made DVD players have emerged in the interstices between communal and individual modes of media consumption. Mukherjee and Singh call them mobile media assemblages, as they play videos not just from DVDs but also from microSD cards, which means that "DVD players no longer just support DVDs, and microSD cards do not remain exclusive to mobile phones and their users. To make the microSD card compatible with new DVD players, various cheap USB adaptors have flooded the local market." ${ }^{29}$ If we were to think of these practices in terms of their archival kernels, the audio cassette, VCD/DVD, or the microSD card all encourage individual/private storage of an exclusive set of data while holding key interest in sites of communal storage, whether it be a retail vendor or a download kiosk with its laptops/desktops and their classified storage. The user, therefore, maintains both personal and communal archives, knowing fully well the vulnerabilities of breakdown with unreliable devices. ${ }^{30}$ Cassettes, disks, or cards may get corrupted as easily as the players may stop working. The first idea of the archive, therefore, is one where storage and access to material always remain unreliable and site-specific. Even though one approaches a shop as a buyer within the informal economy, the archive is constituted by two unstable pieces-both struggling with the precarity of livelihood and lowend technology products. The working-class settlements, precarious wage labor employment, mobile shops or download kiosks, "makeshift" devices, illegal economy of downloads, and tricky format conversions specific to mobile phones' storage and player types constitute a lifeworld of citizen-archive duality in which no bounding block appears stable enough to hold its ground.

The second idea of the archive pertains to YouTube, which offers a paradigm shift as long as the user has access to sufficient internet bandwidth. YouTube offers itself as an oceanic archive, which contains nearly every vernacular music document produced. With increasing formalization of the economy, video production companies are incentivized to upload their entire portfolio so that they can harvest user hits and monetize them with ad revenues. In this ever-expanding archive, access remains "free" as long as one concedes some attention to the advertisements, and navigation remains fluid, either via autoplay or on account of the rich metadata. The remaining site of instability is internet bandwidth. If one wants to access the free archive, one must subscribe to internet data packs or plug into broadband connections. As it turns out, cheaper data packs have indeed encouraged many more to stream 
videos instead of maintaining personal storage and offline consumption. Yet, the battle over the prevailing idea of archive continues. The nature of archive, it must not be forgotten, indicates the character of citizenship rights. Formalization as a drive cannot entirely continue without the formalization of labor laws, fair wage employment, reliable working-class housing, and social security. YouTube's effort to appropriate the informal economy within its formal fold is thus challenged by the precarious conditions of production which prevail and of which vernacular music is an exemplar. Most of the time, these "not-yet" citizens cannot simply walk into a stable archive, despite its pretensions of free and limitless access.

The third key idea of the archive, therefore, manifests the life of informality in the time of platformization. The instability of shifting arbitrage platforms, and unstable access to platform infrastructure, alleviates any threat to the vitality of eclectic, informal, unpredictable, and visceral performative virtuosity of live concerts. It is only popular memory, in all its creative remembering quite unlike objective documentation, which resembles the archive. Yet, memory does not quite follow the archive's structural and bureaucratic guidelines. It may be a stretch to say that the archive comes undone at the site which celebrates ephemerality, but the live concert certainly offers the kernel of an informal lifeworld in which "unequal" migrant citizens claim temporary sovereignty as a mass public. If the mainstream archive of academic history relies too heavily on public institutions, the archive of popular culture traditionally departs from the regimental control of statist narratives. In its departure, however, the informal archive remains "unreliable," self-contradictory, and often overdetermined.

The performative spectacles are not so much the site of consuming the musical composition as a product, but the preeminent site where the performance is served to popular will. If the archive crystallizes the sedimentations of time, whether or not arranged in neat classifications, the loud and full-frontal publicness of Bhojpuri live concerts in particular defies boththe gradual layering of time and neat organization of generic clusters. Yet, the archival play at the live concerts entails the assertive publicness of Bhojpuri language. After all, the step outside the legal-economic stranglehold over media also endorsed a step outside the public shaming and subversion of vernacular languages. The third idea of the archive, then, performatively confronts the normative assumption that Bhojpuri, among other so-called dialects, belongs in private everyday realms. The archive is, first and foremost, a public resource, even if accessing it entails certain qualifications. What the assertive emergence of Bhojpuri and other vernacular music cultures indicates is the clinching convergence of a two-faced arbitrage: (1) the translation of private reveries into public assertions, and (2) the takeover of women's songs into a very masculine assertion of scandalous publicness. ${ }^{31}$ In this way, the "hidden treasure" of private archives is reclaimed for quasi-regionalist assertions in the public realm, which is duly mounted by a variety of male "stars." ${ }^{32}$ While arbitrage platforms have enabled and sustained the growth of this public assertion, and the platform economy could stretch that support further, the individual or communal consumption of vernacular media cannot possibly compensate for the spectacular publicness of a Bhojpuri live concert.

The inclusion of the Bhojpuri archive within the platform economy is, therefore, marked by the logic of overflow-it is the live concerts and a vast offline transaction economy which partly overflows into the digital environs of platformization. The interpenetration between a media industry and the live concert qualifies and reframes informality vis-à-vis platformization. The 
informal mobile media assemblages, on the other hand, work with makeshift devices prone to breakdown, dodgy internet bandwidths, and corruptible files, yet privileging direct ownership and access. The performative assertions of the Bhojpuri concerts are, in effect, distributed over these platforms and assemblages-the presence first celebrated in flesh and blood is relayed across all manner of devices and screens.

\section{Conclusion}

This article has discussed three primary ideas of informality: first, in terms of dubious transactions of authentic or counterfeit media commodities; second, as the lifeblood of an event that stages code-switching across various registers of performative virtuosity; third, as an everyday condition in which livelihood and pleasure are communally implicated, to the extent that one appears to be suspended between formal-legal relations, not necessarily aware or concerned about the imperatives of law. Arbitrage platforms emerged to translate the third order of informality toward the first two. They were variously supported by a moment of enthusiasm and opportunity for creative producers as well as distributors. Whether they sought a sale price or rent on services, the arbitrage platforms helped unearth the everyday archive of cultural wealth and set it in motion as objects and services in economic circulation. This led to an unprecedented expansion of the popular archive with the interpenetration of new motifs, intersections, and ambitions.

YouTube in particular has harvested this relentlessly growing archive in exchange of freedom to access and stream the videos on personal devices. Thus, it would appear that the orders of informality could finally be abandoned-with the producers given the incentive of ad revenues and the viewers able to effortlessly stream content, thereby bringing it all within the formal fold. If it were that easy, YouTube would become the default popular archive for vernacular media, making other arbitrage platforms redundant. However, this article has explored a fundamental tension between the performative informality of live concerts and the distributive control of platform economy. As we have recounted, while arbitrage platforms offered a way to step outside the traditional media platforms, platform economy does not take a similarly benign look at informality. The trajectory of platformization is, therefore, also that of identifying new consumer demographics, whose attention could be monetized in due time.

The monopolistic outreach of digital platforms is propelled by a relentless force to disembed, aggregate, and reorganize via algorithms a new formal order of media consumption. While this certainly threatens the informal media markets, they have thrived by maintaining a curious balance. The formalization drive of the platform economy-so that capital flow and consumer attention are controlled-can certainly sit beside, and feed off, the live concert spectacle and its repeated affirmations of the popular mandate. It can harvest ever more hits and correlate consumer analytics to be sold to advertisers. But the assertive publicness of Bhojpuri popular culture, as with other vernacular media, is testament to the desire to untether such control over the popular archive.

Indeed, Bhojpuri popular culture has been only one of the many intermediate beneficiaries of "vernacularization." The rise of Haryanvi and Uttarakhandi music would be particularly notable alongside Bhojpuri media. Most of these quasi-industrial units have benefited from 
informal media economy and performative virtuosity upholding a linguistic constellation not delivering cultural exactitude as much as a sovereign public assertion of cultural alterity to the imagined mainstream. The two distinct features of such formations have been labor migration of young men to metropolitan centers and the resultant gender divisions further amplified by popular culture. The playful negotiation of sociopolitical and legal-technical boundaries, in effect, works in tandem-transgressive proclamations defying public decency with respect to gender relations and the above-discussed prevailing ideas of informality co-constitute the vernacular media economy, in which platformization has made substantial inroads.

${ }^{1}$ Dr. Akshaya Kumar received the PhD degree in Film and Television Studies from the University of Glasgow, UK. He joined IIT Indore in December 2017 as an assistant professor in the School of Humanities and Social Sciences. His essays have appeared in Postmodern Culture, Social Text, Television and New Media, and various other journals. His forthcoming monograph with Oxford University Press is titled "Provincializing Bollywood: Bhojpuri Cinema in the Comparative Media Crucible."

${ }^{2}$ See Ratnakar Tripathy, "Music Mania in Small-Town Bihar: Emergence of Vernacular Identities," Economic and Political Weekly 67 (22, 2012): 58-66; Ratnakar Tripathy, "The Artist as Entrepreneur: Talent, Taste, and Risk in Haryana and Bihar," in The Indian Media Economy: Industrial Dynamics and Cultural Adaptation, vol. I, ed. Adrian Athique, Vibodh Parthasarathi, and S. V. Srinivas (New Delhi: Oxford University Press, 2018), 197-213.

${ }^{3}$ See Vishal Rawlley, Miss Use: A Survey of Raunchy Bhojpuri Music Album Covers (Tasweer Ghar: A Digital Archive of South Asian Popular Visual Culture, 2007), http://tasveergharindia.net/cmsdesk/essay/66/index.html.

${ }^{4}$ Rahul Mukherjee and Abhigyan Singh, "Reconfiguring Mobile Media Assemblages: Download Cultures and Translocal Flows of Affective Platforms," Asiascape: Digital Asia 4 (2017): 257-84; M. Rashmi, "The Offline Media Economy: Digitally Marginalized Users of Mobile Phones," in The Indian Media Economy, vol. II: Market Dynamics and Social Transactions, ed. Adrian Athique, Vibodh Parthasarathi, and S. V. Srinivas (New Delhi: Oxford University Press, 2018), 202-19.

${ }^{5}$ See Akshaya Kumar, "Bhojpuri Consolidations in the Hindi Territory: Infrastructure, Aesthetics and Competing Masculinities in North India," BioScope: South Asian Screen Studies 7 (2, 2016): 189-206; Akshaya Kumar, "Deswa, the Film and the Movement: Taste, Industry and Representation in Bhojpuri Cinema," Contemporary South Asia 26 (1, 2018): 69-85.

${ }^{6}$ Ramon Lobato and Julian Thomas, The Informal Media Economy (Hoboken, NJ: John Wiley, 2015).

${ }^{7}$ Peter Manuel, Cassette Culture: Popular Music and Technology in North India (Chicago, IL: University of Chicago Press, 1993).

${ }^{8}$ See Tripathy, "The Artist as Entrepreneur."

${ }^{9}$ Adrian Athique makes a similar observation about the "disorganized" Indian film economy of the twentieth century, which has gone through remarkable consolidation in this century. See Adrian Athique, "The Global Dynamics of Indian Media Piracy: Export Markets, Playback Media and the Informal Economy," Media, Culture E Society 30 (5, 2008): 699-717. 
${ }^{10}$ Rashmi, "The Offline Media Economy."

${ }^{11}$ Mukherjee and Singh, "Reconfiguring Mobile Media Assemblages," 260.

${ }^{12}$ Ibid., 261-63.

${ }^{13}$ Adrian Athique, Vibodh Parthasarathi, and S. V. Srinivas, The Indian Media Economy: Industrial Dynamics and Cultural Adaptation, vol. 1. (New Delhi: Oxford University Press, 2018); Adrian Athique, Vibodh Parthasarathi, and S. V. Srinivas, The Indian Media Economy: Market Dynamics and Social Transactions, vol. 2. (New Delhi: Oxford University Press, 2018).

${ }^{14}$ Jonathan Beller, "Informatic Labor in the Age of Computational Capital," Lateral: Journal of the Cultural Studies Association 5 (1, 2016), doi:10.25158/L5.1.4; Jonathan Beller, "The Programmable Image of Capital: M-I-C-I'-M' and the World Computer." Postmodern Culture 26 (2, 2016), doi:10.1353/pmc.2016.0005.

${ }^{15}$ Nick Couldry and Ulises A. Mejias, "Data Colonialism: Rethinking Big Data's Relation to the Contemporary Subject," Television \& New Media 20 (4, 2019): 336-49.

${ }^{16}$ Akshaya Kumar, "Media Portfolios after Credit-Scoring: Attention, Prediction, and Advertising in Indian Media Networks," Postmodern Culture 28 (2, 2018), doi:10.1353/ pmc.2018.0014.

${ }^{17}$ S. V. Srinivas, "Politics in the Age of YouTube: Degraded Images and Small Screen Revolutions," in Asian Video Cultures: In the Penumbra of the Global, ed. Joshua Neves and Bhaskar Sarkar (Durham, NC: Duke University Press, 2017), 217-39.

${ }^{18}$ Ramon Lobato, "The Cultural Logic of Digital Intermediaries: YouTube Multichannel Networks," Convergence 22 (4, 2016): 348-49.

19 Ibid., 351.

20 Ibid.

${ }^{21}$ Ibid., 356.

${ }^{22}$ Ibid., 357.

${ }^{23}$ Adrian Athique, "Integrated Commodities," in The Indian Media Economy, vol. 2: Market Dynamics and Social Transactions, ed. Adrian Athique, Vibodh Parthasarathi, and S. V. Srinivas (New Delhi: Oxford University Press, 2018), 23-36.

${ }^{24}$ PatrickVonderau, "The Video Bubble:MultichannelNetworks and the Transformation of YouTube," Convergence 22 (4, 2016): 361-75.

${ }^{25}$ Ivan Ascher, Portfolio Society: On the Capitalist Mode of Prediction (Cambridge, MA: The MIT Press, 2016).

${ }^{26}$ Brahma Prakash, Cultural Labour: Conceptualizing the "Folk Performance" in India (New Delhi: Oxford University Press, 2019), 179.

${ }^{27}$ Kumar, "Deswa, the Film and the Movement."

${ }^{28}$ Mukherjee and Singh, "Reconfiguring Mobile Media Assemblages," 265.

${ }^{29}$ Ibid., 266.

${ }^{30}$ See Brian Larkin, Signal and Noise: Media, Infrastructure, and Urban Culture in Nigeria (Durham, NC: Duke University Press, 2008).

${ }^{31}$ See Asha Singh, "Of Women, by Men: Understanding the 'First Person Feminine' in Bhojpuri Folksongs," Sociological Bulletin 64 (2, 2015): 171-96; Smita Tewari Jassal, Unearthing Gender: Folksongs of North India (Durham, NC: Duke University Press, 2012).

${ }^{32}$ Kumar, "Bhojpuri Consolidations in the Hindi Territory." 


\section{Bibliography}

Ascher, Ivan. Portfolio Society: On the Capitalist Mode of Prediction. Cambridge, MA: The MIT Press, 2016.

Athique, Adrian. "Integrated Commodities." In The Indian Media Economy, vol. 2: Market Dynamics and Social Transactions, edited by Adrian Athique, Vibodh Parthasarathi, and S. V. Srinivas, 23-36. New Delhi: Oxford University Press, 2018.

Athique, Adrian. "The Global Dynamics of Indian Media Piracy: Export Markets, Playback Media and the Informal Economy." Media, Culture \& Society 30, no. 5 (2008): 699-717.

Athique, Adrian, Vibodh Parthasarathi, and S. V. Srinivas. The Indian Media Economy: Industrial Dynamics and Cultural Adaptation. Vol. 1. New Delhi: Oxford University Press, 2018a.

Athique, Adrian, Vibodh Parthasarathi, and S. V. Srinivas. The Indian Media Economy: Market Dynamics and Social Transactions. Vol. 2. New Delhi: Oxford University Press, 2018b.

Beller, Jonathan. "Informatic Labor in the Age of Computational Capital." Lateral: Journal of the Cultural Studies Association 5, no. 1 (2016a). doi:10.25158/L5.1.4.

Beller, Jonathan. "The Programmable Image of Capital: M-I-C-I'-M' and the World Computer." Postmodern Culture 26, no. 2 (2016b). doi:10.1353/pmc.2016.0005.

Couldry, Nick, and Ulises A. Mejias. "Data Colonialism: Rethinking Big Data's Relation to the Contemporary Subject." Television \& New Media 20, no. 4 (2019): 336-49.

Jassal, Smita Tewari. Unearthing Gender: Folksongs of North India. Durham, NC: Duke University Press, 2012.

Kumar, Akshaya. "Bhojpuri Consolidations in the Hindi Territory: Infrastructure, Aesthetics and Competing Masculinities in North India." BioScope: South Asian Screen Studies 7, no. 2 (2016): 189-206.

Kumar, Akshaya. "Deswa, the Film and the Movement: Taste, Industry and Representation in Bhojpuri Cinema." Contemporary South Asia 26, no. 1 (2018a): 69-85.

Kumar, Akshaya. "Media Portfolios after Credit Scoring: Attention, Prediction and Advertising in Indian Media Networks." Postmodern Culture 28, no. 2 (2018b). doi:10.1353/ pmc.2018.0014.

Larkin, Brian. Signal and Noise: Media, Infrastructure, and Urban Culture in Nigeria. Durham, NC: Duke University Press, 2008.

Lobato, Ramon. "The Cultural Logic of Digital Intermediaries: YouTube Multichannel Networks." Convergence 22, no. 4 (2016): 348-60.

Lobato, Ramon, and Julian Thomas. The Informal Media Economy. Hoboken, NJ: John Wiley, 2015.

Manuel, Peter. Cassette Culture: Popular Music and Technology in North India. Chicago: University of Chicago Press, 1993.

Mukherjee, Rahul, and Abhigyan Singh. "Reconfiguring Mobile Media Assemblages: Download Cultures and Translocal Flows of Affective Platforms." Asiascape: Digital Asia 4 (2017): 257-84. 
Prakash, Brahma. Cultural Labour: Conceptualizing the "Folk Performance" in India. New Delhi: Oxford University Press, 2019.

Rashmi, M. "The Offline Media Economy: Digitally Marginalized Users of Mobile Phones." In The Indian Media Economy, vol. II: Market Dynamics and Social Transactions, edited by Adrian Athique, Vibodh Parthasarathi, and S. V. Srinivas, 202-19. New Delhi: Oxford University Press, 2018.

Rawlley, Vishal. "Miss Use: A Survey of Raunchy Bhojpuri Music Album Covers." Tasweer Ghar: A Digital Archive of South Asian Popular Visual Culture, 2007, http://tasveergharin dia.net/cmsdesk/essay/66/index.html.

Singh, Asha. "Of Women, by Men: Understanding the 'First Person Feminine' in Bhojpuri Folksongs." Sociological Bulletin 64, no. 2 (2015): 171-96.

Srinivas, S. V. "Politics in the Age of YouTube: Degraded Images and Small Screen Revolutions." In Asian Video Cultures: In the Penumbra of the Global, edited by Joshua Neves and Bhaskar Sarkar, 217-39. Durham, NC: Duke University Press, 2017.

Tripathy, Ratnakar. "Music Mania in Small-Town Bihar: Emergence of Vernacular Identities." Economic and Political Weekly 67, no. 22 (2012): 58-66.

Tripathy, Ratnakar. "The Artist as Entrepreneur: Talent, Taste, and Risk in Haryana and Bihar." In The Indian Media Economy: Industrial Dynamics and Cultural Adaptation, vol. I, edited by Adrian Athique, Vibodh Parthasarathi and S. V. Srinivas, 197-213. New Delhi: Oxford University Press, 2018.

Vonderau, Patrick. "The Video Bubble: Multichannel Networks and the Transformation of YouTube." Convergence 22, no. 4 (2016): 361-75. 